Contributions to Game Theory and Management, XIII, 142-151

\title{
Coalition Power Estimation. Overview from the Mathematical and Philosophical Perspectives ${ }^{\star}$
}

\author{
Ekaterina V. Gromova ${ }^{1}$ and Igor I. Evlampiev ${ }^{2}$ \\ 1 St.Petersburg State University, \\ Faculty of Applied Mathematics and Control Processes, \\ St.Petersburg, Russia; \\ E-mail: e.v.gromova@spbu.ru \\ 2 St.Petersburg State University, Institute of Philosophy, \\ St.Petersburg, Russia; \\ E-mail: yevlampiev@mail.ru
}

\begin{abstract}
The paper studies the problem of measuring the strength of a coalition in terms of the mathematical game theory and social philosophy. This work is an interdisciplinary study.

Keywords: cooperative games, characteristic function, social philosophy, Christian ideal of society.
\end{abstract}

\section{Introduction}

A cooperative game consists of a finite set of players $N$, called the grand coalition, and a characteristic function $V: 2^{N} \rightarrow \mathbb{R}$ that maps the set of all possible coalitions to the set of real numbers and which satisfies the condition $V(\emptyset)=0$. The function $V(S)$ describes the worth or power of a coalition, i.e., how much collective payoff a set of players $S$ can gain by forming a coalition. Thus the characteristic function is a key component of a cooperative game (see, e.g., Neumann and Morgenstern, 1953).

The crucial issue here is the way the players from coalition $S$ interact with the rest of players from the set $N \backslash S$. The analysis of such an interaction is the main contribution of the paper.

Nowadays, there exist different approaches to calculate the characteristic function in a cooperative game. Some of them are described in (Reddy and Zaccour, 2014 ) with a modern view on the subject for the static formulation. For the dynamic formulation, the construction of the so-called $\alpha$ - (Neumann and Morgenstern, 1953) and $\delta$ - characteristic functions (see (Petrosjan and Danilov, 1982) and (Petrosjan and Zaccour, 2003)) was analyzed in (Gromova and Petrosyan, 2017) where an approach for the construction of a $\zeta$-characteristic function was introduced (see also (Petrosyan and Gromova, 2014) for the first reference in Russian).

In (Gromova and Marova, 2018a; Gromova et al., 2020) a $\zeta$ - characteristic function was introduced, and a new characteristic of players' behavior, referred to as the reaction measure, was defined. This measure shows the effect of the choice of strategies by the players from coalition $S$ and anti-coalition $N \backslash S$ to the payoff of coalition $S$. Moreover, we consider a new type of interaction in which the players from coalition $S$ do not react to the behavior of players from $N \backslash S$ and use their strategies from the optimal profile (which for $n$ players corresponds to the maximal total payoff), while the players from $N \backslash S$ do not react to the players from $S$ as well

\footnotetext{
* The reported study was funded by RFBR according to the research project N 18-0000727 (K) (18-00-00725, 18-00-00628)
} 
and use their strategies from the Nash equilibrium (calculated for all $n$ players). In this way, we introduce a new characteristic function which is technically much easier to construct. Its properties were studied in a general setting, and it was concluded that the new function can be used as a substitute for the classical $\alpha$-characteristic function.

A systematic overview of $\alpha-, \delta$ -,$\zeta$ - and $\eta$-characteristic function and their properties is presented in (Gromova et al., 2020).

This paper provides an interdisciplinary analysis of $\alpha-, \delta$-, $\zeta$ - and $\eta$-characteristic function from the mathematical and philosophical perspectives on the base of the type of coalition $S$ and anti-coalition $N \backslash S$ interaction.

The most essential tool for understanding the mechanisms of behavior of social groups is not the study of economically rational patterns of using various resources, but rather the study of the it ethics of behavior, which is largely based on belonging to a particular religious concept.

Society in its development is changing under the influence of various factors. One of them is a new religion. Introducing itself into the consciousness of people, religion instills new stereotypes of attitude towards oneself and others, thus leading to the gradual destruction of old ties and social communities and the formation of new ones. It may seem that the mechanism of action of religious ideas on various spheres of society is very complex and difficult to describe using reasonably simple models. Nevertheless, with the development of social philosophy and sociology, studies began to appear that showed the possibility of a rational and straightforward description of the influence of religious beliefs on people's behavior.

In this paper, an attempt is made to compare mathematical models corresponding to different methods of constructing a characteristic function in a cooperative game, and models of social philosophy that explain various stereotypes of interaction between social groups and society.

\section{Mathematical Problem Statement}

Currently, game theory distinguishes between a large number of game types, (Petrosyan et al., 2012). However, non-cooperative and cooperative games are fundamentally different in terms of the specific tasks being solved. When studying the optimal behavior of players in non-cooperative games, these games are usually considered in normal form, that is, as a system $\Gamma=<N,\left\{X_{i}\right\}_{i \in N},\left\{K_{i}\right\}_{i \in N}>$, where $N=\{1,2, \ldots, n\}$ is the set of players, $X_{i}$ is the set of $i$ th player strategies, $K_{i}$ is the payoff function of the $i$ th player defined on $X=\prod_{i=1}^{n} X_{i}$. The conflict of interests comes from the fact that each player $i, i \in N$, solves the task of choosing one of the strategies $u_{i} \in X_{i}$ that maximizes the payoff $K_{i}$ of this player, which depends, among other things, on the selected strategies of other players. In this sense, the approach to solving the range of tasks in a non-cooperative formulation of the game can be called "strategic" (Petrosjan and Danilov, 1982).

In a cooperative setting, all players agree to act together optimally (cooperatively) before the start of the game, i.e. they agree to use optimal strategies $\bar{u}=\left(\bar{u}_{1}, \bar{u}_{2}, \ldots, \bar{u}_{n}\right)$, maximizing the total payoff $V(N)=\max _{u \in X} \sum_{i=1}^{n} K_{i}(u)$. Under rather weak restrictions on the problem, it is simple enough to find optimal strategies $\bar{u}=\left(\bar{u}_{1}, \bar{u}_{2}, \ldots, \bar{u}_{n}\right)$. In the cooperative version of the game, the main task of conflict nature is the problem of a fair division of $V(N)$ between players. In 
this regard, the approach to solving problems in cooperative games can be called "non-strategic", emphasizing that the problem of finding optimal strategies is not of a conflicting nature and is not the main one.

The determination of the set of imputations is based on the function $V(\cdot)$, which is called the characteristic function (Pechersky and Yanovskaya, 2004). In the general case, a cooperative game is defined as a pair $\langle N, V(\cdot)\rangle$, where $N=$ $\{1,2, \ldots, n\}$ is the set of players, $V(S), S \subseteq N$ is a characteristic function defined on the set of admissible coalitions. Initially, the value of the characteristic function $V(S)$ was interpreted as the maximum guaranteed payoff of the coalition $S$ that it can receive by acting independently of other players (Petrosjan and Danilov, 1982, Neumann and Morgenstern, 1953). However, at the moment, under the characteristic function, as a rule, is meant a mapping that puts in correspondence with any admissible coalition $S$ a value showing the "strength" of this coalition (Pechersky and Yanovskaya, 2004).

Now consider different interaction models of the coalition $S$ and the remaining players from $N \backslash S$.

\section{1. $\alpha$-characteristic function}

A classical approach of construction the characteristic function is called the $\alpha$-characteristic function. It was introduced in (Neumann and Morgenstern, 1953) and was the only way to construct a cooperative game for a long time. The main idea of this method is using the lower value of the zero-sum game $\Gamma_{S, N \backslash S}$ between the coalition $S$ as the first player and coalition $N \backslash S$ as the second player.

$$
V^{\alpha}(S)= \begin{cases}0, & S=\emptyset, \\ \max _{\substack{u_{i}, i \in S}} \min _{\substack{u_{j}, j \in N \backslash S}} \sum_{i \in S} K_{i}(u), S \subseteq N .\end{cases}
$$

We assume that the maximum and minimum are achieved in (1). The value $V^{\alpha}(S)$ is interpreted as the maximum value that coalition $S$ can get when the $N \backslash S$ acts against $S$.

\section{2. $\delta$-characteristic function}

The technique of construction the $\delta$-characteristic function was proposed in (Petrosjan and Zaccour, 2003). The process of calculation of this function consists of two steps. Firstly, one has to calculate the Nash equilibrium strategies for all players. Secondly, players from $S$ maximize their total payoff $\sum_{i \in S} K_{i}$ while players from $N \backslash S$ use strategies from the Nash equilibrium.

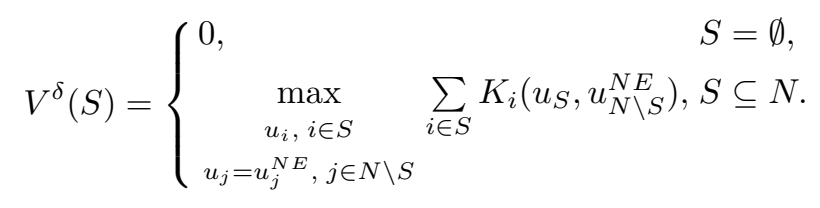

This form of the characteristic function requires fewer computational operations comparing with $\alpha$-characteristic function. Additionally, previously constructed the Nash equilibrium simplifies the computation of $V^{\delta}(S)$. Moreover, (2) has a practical, economical interpretation. Players not from the coalition $S$ do not trend to form anti-coalition $N \backslash S$ in real models. 


\section{3. $\quad \zeta$-characteristic function}

The $\zeta$-characteristic function was introduced in (Gromova and Petrosyan, 2017). The first step of calculation of this characteristic function for coalition $S$ is finding optimal controls maximizing the total payoff of the players. On the second step players from the coalition $S$ use the optimal cooperative strategies while the leftout players from $N \backslash S$ use the strategies minimizing the total payoff of the players from $S$.

$$
V^{\zeta}(S)=\left\{\begin{array}{lr}
0, & S=\emptyset, \\
\min _{\substack{u_{j} \in U_{j}, j \in N \backslash S, u_{i}=u_{i}^{*}, i \in S}} \sum_{i \in S} K_{i}\left(u_{S}^{*}, u_{N \backslash S}\right), S \subseteq N .
\end{array}\right.
$$

The constructed $V^{\zeta}(S)$ is superadditive in general (Gromova and Petrosyan, 2017). Additionally, already computed optimal controls are used for $\zeta$-characteristic function which simplifies the computation process comparing with $\alpha$-characteristic function. Besides, these controls exist and could be found for a wide class of games under rather weak constraints. Lastly, $\zeta$-characteristic function is applicable for games with fixed coalition structures (Petrosyan and Gromova, 2014).

\section{4. $\eta$-characteristic function}

The idea of $\eta$-characteristic function was presented in (Gromova and Marova, 2018a). This characteristic function bases on strategies from the optimal profile $u^{*}$ and strategies from the Nash equilibrium $u^{N E}$. We will use $u_{S}^{*}$ for players from $S$ (as in $\zeta$-characteristic function) and $u_{N \backslash S}^{N E}$ for players from $N \backslash S$ (as in $\delta$-characteristic function).

$$
V^{\eta}(S)=\left\{\begin{array}{lr}
0, & S=\emptyset, \\
\sum_{i \in S} K_{i}\left(u_{S}^{*}, u_{N \backslash S}^{N E}\right), & S \subseteq N .
\end{array}\right.
$$

This function models the case when players from $N \backslash S$ decide instead of optimal strategies use strategies from the Nash equilibrium $u^{N E}$.

Construction of $\eta$-characteristic function has some technical advantages. It is much simpler in terms of calculation comparing with $\alpha$-characteristic function. As mentioned above, optimal controls exist and could be found for a wide class of games. The drawback of this function is the problem of existence and uniqueness of Nash equilibrium solution (Gromova et al., 2020).

\section{Philosophical Interpretation of Coalition and Anti-coalition Interaction}

The mathematical methods for assessing coalition strength that are described above can be interpreted in terms of social philosophy. One of the most important factors explaining the behavior of social groups of people is their belonging to one or another religious group and its fundamental concept, i.e. stereotypes of behavior that determine the interaction of members of this group with the outside world. It is worth noting that the division based on belonging to a particular ideology is also responsible for the nature of the relationship of the surrounding world with this group, i.e., this process is not one-sided. 


\section{1. $\quad \alpha$ and $\delta$ characteristic functions}

A classic example of a study of the influence of religious beliefs on human behavior is Max Weber's book (Weber, 1905) "The Protestant Ethics and the Spirit of Capitalism" (Die protestantische Ethik und der Geist des Kapitalismus, 1905). Weber was able to explain why the countries with Protestant religiosity in the 1719 centuries achieved much greater economic development than the countries that retained Catholic religiosity. As Weber showed, such concepts as "divine predestination" and "salvation of the soul", far from economic life, in their understanding, characteristic of Protestantism, had a fundamental impact on the economic ethics of Protestants. Furthermore, this in turn determined completely different forms of economic life and the pace of development of Protestant countries in comparison to the Catholic.

Weber considered the state of a society when religious beliefs are universal and generally accepted, and society is homogeneous with respect to this factor. However, very often we have a situation in which religious communities exist in a social environment that does not accept their beliefs. This situation happens when we consider an early stage in the development of religion or a new kind of religion, or a religious community, forced to exist in a different religion (for example, early Christian communities in a pagan environment or Jewish communities in an Islamic or Christian society). Such an attitude of the religious community towards the social environment can be quite easily described within the framework of formal models. The situation of the antagonistic relationship of the social environment to a cohesive religious community can be correlated with the notion of the $\alpha$-characteristic function. The case when the social environment takes a neutral position can be described using the $\delta$-characteristic function. In these models, it is assumed that the main goal of the religious community is its survival and its good; the surrounding society and people outside the community are considered only as a possible threat to its existence.

\section{2. $\quad \zeta$ and $\eta$ characteristic functions}

However, since the emergence of Christianity led to the emergence of radical religious ethics, in which members of the community have as their goal not only their good but also the good of those around them, an utterly different model is required to describe this situation. It should be noted that already at the time of its birth, the Christian worldview was quite contradictory in content and also it underwent significant changes in history. Therefore, we first turn our attention to early Christianity, which was distinguished by more definite and harsh principles than its later forms. In early Christianity, two components can be distinguished. On the one hand, the highest goal is to serve God and the desire for salvation, which is understood as the final parting with earthly reality and the transition to the kingdom of heaven.

On the other hand, in the organization of earthly life, early Christianity put forward principles that were sharply opposed to the natural egoism of people. In the ethics that Jesus Christ preached, according to the gospels, the main principles were love for all people without exception ("love thy neighbor as yourself" (Matthew 22, 39)) and ministry not so much to their individual interests as to the interests of all. In its most complete form, such an understanding of the goals of people's lives was embodied precisely by the early Christians; their communities were communities of saints, i.e., people who radically diverged from accepted norms of life. At the 
same time, in the first period of its development, Christianity met with a hostile attitude. That is to say, there were small communities of Christians who promoted the equality of all people before God and the service of the common good, not the good of their personality, and around them there were people who acted against them, against their actions aimed at the benefit of all. It is easy to see that this form of the community's relationship with the social environment is defined by $\zeta$-characteristic function.

Over time, the new moral principles of religion, gaining a more general character, lose their certainty and exactness and remain as "ideal" norms. However, they no longer strongly affect real life and become less effective. As a result, the distinction between entities that are members of religious communities from those who are not members of them is diminishing. In the history of Christianity, a radical turning point came after it was declared by the emperor Constantine in the 4th century the state religion of the Roman Empire. This process was very clearly described by the Russian philosopher of the late 19th century, Vladimir Solovyov: "Under Constantine the Great and Constance, pagan masses were brought to Christianity not by conviction, but by slavish imitation or mercenary calculation. There was an unprecedented type of feigned, hypocritical Christians. It multiplied even more when under Theodosius, and finally under Justinian, paganism was forbidden by law and $\langle\ldots\rangle$ every subject of the Greco-Roman Empire was forcibly obligated to be a Christian under pain of heavy criminal punishments. $<\ldots>$ The formerly truly Christian society has spread and disappeared into a Christian by name, but in reality - a pagan community. The overwhelming majority of superficial Christians not only preserved the pagan principles of life under a Christian name, but tried in every way - instinctively, and partly also consciously - to affirm alongside Christianity, legitimize and perpetuate the old pagan order" (Solovyev, 1988).

The weakening of the influence of religion on people's lives means a crisis, and it is realized by people who are beginning to reflect on what is wrong in religion and striving to introduce new ideas into the religion that should give it greater vitality. Concerning the essence and historical fate of Christianity, the thoughts of F. Dostoevsky and L. Tolstoy are especially important. In fact, in the works of two great Russian writers and philosophers, a new interpretation of Christianity was developed as a system of principles that should radically change people's lives.

Dostoevsky and Tolstoy were equally critical of traditional church Christianity, which, in their opinion, has long failed to fulfill its role in society and did not lead people and the whole society to perfection. Both writers understood Jesus Christ not as God embodied in man, but as a man who gives an example of an ideal life for all people. Accordingly, in the Christian doctrine, the main thing is not the mythology of "atonement for sins" through the death of Jesus Christ at Calvary, but simply a moral example of life in which a person pursues not his selfish interests, but "serves everyone", i.e., lives for the benefit of all, and not for himself. We can say that Russian thinkers tried to return Christianity to its original, "ideal" model. Here is how Dostoevsky wrote about this in a very famous manuscript sketch created on the day of the death of his first wife Marya Isaeva: "Meanwhile, after the appearance of Christ as the incarnation ideal of man, it has become clear that the highest, the final development of the personality should lead precisely to the point $\langle\ldots\rangle$ where man finds, realizes and become convinced with all the strength of his nature that the highest use which man can make of his personality, of the fullness of the 
development of his I, is as it were to destroy that I, to give it over wholly to each and everyone, wholeheartedly and selflessly. This is the greatest happiness. $<\ldots>$ This is precisely the paradise of Christ. All history, both of humanity and to some extent of each person separately, is only development, struggle, striving, and attainment of this goal" (Tolstaya, 2013).

According to the traditional Christian convictions that the Christian church proclaims, the highest goal of life for all people is the kingdom of heaven, this being outside of earthly reality, where a person cannot achieve an ideal state. In contrast, Dostoevsky argues that the true meaning of Christianity is to achieve an ideal, perfect state in earthly reality itself, in the history of mankind, by changing the moral principles of people. Dostoevsky calls this perfect state "the paradise of Christ," because it can only be achieved if people live according to the moral principles that Christ proclaimed: to love others as himself and even more than himself, and to serve not his own interests, but the interests of others. This means that every person must become completely like Christ, as he is depicted in the gospels. Dostoevsky speaks about this many times in his works. Here is the most explicit quote on this subject from the preparatory materials for the novel "Demons": "If people had not the slightest idea about the state and about any sciences, but would have been all like Christ, is it possible that there would be no heaven on earth right now so?" (Dostoevsky, 1974). One of the main ideological character of Dostoevsky, the Orthodox elder Zosima, in the novel "The Brothers Karamazov" says about the opportunity to reach heaven on earth: "life is paradise, and we are all in paradise, but we won't see it; if we would, we should have heaven on earth the next day" (Dostoevsky, 1994).

The same tendency to understanding Christianity is present in the later works of Leo Tolstoy. He very sharply criticizes church doctrine for distorting the true teachings of Jesus Christ, for the fact that it replaced the real earthly goals of life with some unreal, heavenly ones. Tolstoy argues that the essence of Christ's teachings is to demonstrate the lifestyle that will inevitably lead all people, the whole society to an ideal state, to "paradise on earth." Tolstoy speaks about this, for example, in the work "What is my faith?": "The kingdom of God upon earth consists in this, that all men should be at peace with one another. $<\ldots>$ Peace among men is the greatest blessing that can exist upon this earth, and it is within reach of all men. $\langle\ldots>$ The whole doctrine of Jesus has but one object, to establish peace - the kingdom of God - among men" (Tolstoy, 1885).

In the treatise "On Life", Tolstoy contrasts the majority of ordinary people who pursue their selfish goals or, as he denotes, the goals of their "animal personality", and those who follow the teachings of Christ. "The life of man as an individual, striving only for his own welfare amid an infinite number of similar individuals destroying each other and destroying themselves, is an evil and absurdity - and the true life cannot be such" (Tolstoy, 1934, p. 20). And further about the same: "For an animal which has not reasonable consciousness to show it the wretchedness and finiteness of its existence, the welfare of its personality (and the resulting continuation of the species) is the highest aim of life. But for man personality is not life, it is merely the stage of his existence at which he discovers the true good of life which does not coincide with the good of his personality" (Tolstoy, 1934, p. 68).

Tolstoy believes that the path of true life consists in a radical denial of the natural egoism of an isolated individual and in unconditionally following the principle of 
love for others and serving them: "the greatest good - and one capable of being infinitely increased - for every being can be achieved only by this law of devotion of each to all and accordingly of all to each" (Tolstoy, 1934, p. 77). The difference between Tolstoy's point of view and Dostoevsky's point of view is that he highlights the concept of serving others as the principle of non-resistance to evil by violence because he believes that it is the violence committed by people against each other that primarily separates them and does not allow to love the other as himself.

At the same time, both Dostoevsky and Tolstoy believed that membership in the official church does not at all make people committed to the ideal of Christ; there are very few people living in accordance with this ideal, and they are usually not associated with the church. This was especially emphasized by Tolstoy, who claimed that these "best" people often do not even know the name of Christ, but in their life, they intuitively follow his commandments: "Fortunately there is a remnant, made up of the noblest minds of the age, who are not contented with this religion $<$ Church $>$, but have an entirely different faith with regard to what the life of man ought to be. $\langle\ldots\rangle$ These people, as a general thing, know little of the doctrine of Jesus; they do not understand it, and, like their adversaries, they refuse to accept the leading principle of the religion of Jesus, which is to resist not evil; often they have nothing but a hatred for the name of Jesus; but their whole faith with regard to what life ought to be is unconsciously based upon the humane and eternal truths comprised in the Christian doctrine. This remnant, in spite of calumny and persecution, are the only ones who do not tamely submit to the orders of the first comer. Consequently, they are the only ones in these days who live a reasonable and not an animal life, the only ones who have faith" (Tolstoy, 1885).

Finally, it can be noted that the same idea of the ideal of universal development and the purpose of human history was formulated by the French philosopher Henri Bergson in the book "Two Sources of Morality and Religion" (1932). He argued that history is determined by those people who in their lives follow the ideal of evangelical ethics, that is, the same principles of life that we just spoke about in connection with the interpretation of Christianity by Dostoevsky and Tolstoy. Bergson considered the main thing in this ethic to be love for all people, for all humanity, contrary to that personal and national egoism, which is the property of all ordinary people. According to Bergson, "just as there were brilliant people who pushed the boundaries of the mind and the same individuals were occasionally provided much more than they could immediately give sight, so also gifted souls appeared who felt like kindred to all souls, and instead of to remain within the boundaries of the group and be limited by the solidarity established by nature, in a rush of love rushed to humanity as a whole" (Bergson, 1932, p. 102).

Bergson believed that it was Jesus Christ, who most fully expressed the ideal of a perfect society as a society where everyone loves everyone and serves everyone. Nevertheless, he, like Tolstoy, did not consider historical Christianity and the Christian church to be consistent with this ideal. Absolute morality, about which he speaks, existed before the advent of Christianity and exists rather outside the Christian church today. It is those who follow this morality do determine the future of mankind: "... the great moral personalities who left a mark in history extend their hands to each other through the centuries, through our human cities; together they form a divine city where they invite us to enter. We may not hear their voices distinctly, but the cry is nevertheless cast, and something answers him in the depths 
of our souls. $\langle\ldots\rangle$ they attract us into an ideal society at the very time when we yield to the pressure of a real society" (Bergson, 1932, p. 72).

In accordance with the thoughts of Russian writers and Bergson, society consists of the majority of people who think mainly about their own good, and a small group of "saints" who realize the ideal of Christ as the pursuit of good for everyone and everybody. This model is easy to formalize using the $\eta$-characteristic function. Although usually society is represented differently, with the help of more pragmatic economic, political, social models, great thinkers argue that it is precisely such a model that we must first bear in mind if we want to correctly understand the highest and true goal of the historical development of mankind. If we assume in this model that the number of "saints" included in the group $S$ is continuously increasing, it will be possible to describe the movements of human society to an ideal state, to "heaven on earth".

\section{Conclusion}

In this paper, an attempt is made to compare mathematical models corresponding to different methods of constructing a characteristic function in a cooperative

game, and models of social philosophy that explain various models of interaction between social groups and society.

\section{References}

Bergson, H. (1932). The Two Sources of Morality and Religion (Les Deux Sources de la Morale et de la Religion).

Gromova, E., Petrosyan, L. (2017). On an approach to constructing a characteristic function in cooperative differential games. Automation and Remote Control, 78, 1680-1692.

Gromova, E., Marova, E. (2018). Coalition and anti-coalition interaction in cooperative differential games. IFAC PapersOnLine, 51(32), 479-483.

Gromova, E., Marova, E., Gromov, D. (2020). A substitute for the classical NeumannMorgenstern characteristic function in cooperative differential games. Journal of Dynamics and Games, $\mathbf{7}(\mathbf{2}), 105-122$.

Gromova, E., Marova, E. (2018). On the characteristic function construction technique in differential games with prescribed and random duration. Contributions to Game Theory and Management, 11, 53-65.

Dostoevsky, F.M. (1974). Demons. Preparatory materials. Dostoevsky F.M. Complete works. In 30 volumes. Volume 11. Leningrad: Nauka, P. 193 (in Russian).

Dostoevsky, F.M. (1994). The Brothers Karamazov. Great Books of the Western World. Vol. 52. Dostoevsky. Ibsen. 2d ed. Chicago, Encyclopaedia Britannica, inc., p. 156-157.

von Neumann, J., Morgenstern, O. (1953). Theory of Games and Economic Behavior. Princeton University Press.

Pechersky, S., Yanovskaya, E. (2004). Cooperative games: solutions and axioms. St. Petersburg.

Petrosjan, L., Danilov, N. (1982). Cooperative differential games and their applications; Tomsk University Press: Tomsk.

Petrosyan, L.A., Gromova, E.V. (2014). Two-level cooperation in coalitional differential games. Trudy Inst. Mat. i Mekh. UrO RAN, 20(3), 193-203.

Petrosyan, L.A., Zenkevich, N.A., Shevkoplyas, E.V. (2012). Teoriya igr (Game Theory), St. Petersburg: BKhV-Peterburg.

Petrosjan, L., Zaccour, G. (2003). Time-consistent Shapley value allocation of pollution cost reduction. J. of Economic Dynamics and Control, 27(3), 381-398.

Reddy, P.V., Zaccour, G. (2014). A friendly computable characteristic function. GERAD Research Report G-2014-78. 
Solovyev, V. (1988). About the decline of the medieval worldview. Soloviev V.S. Collected Works. In 2 volumes. M., Vol. 2. P. 342-343 (in Russian).

Tolstaya, Katya (2013).Kaleidoscope: F.M. Dostoevsky and the early dialectical theology. Transl. by Anthony Runia, Brill's Series in Church History, Vol. 61, Leiden, 2013, p. 66.

Tolstoy, Leo (1885). What I Believe. (My Religion.) Trans. from The French by Huntington Smith. New York: Thomas Y. Crowell \& Co., 13 Astor Place. Copyright By Thomas Y. Crowell \& Co. http://www.gutenberg.org/files/43794/43794-h/43794-h.htm

Tolstoy, Leo (1934). On Life and Essays on Religion/ Transl. with an Introduction by Aylmer Maude, Oxford University Press, London: Humphrey Milford.

Vorob'ev, N.N. (1967). Coalitional Games. Teor. Veroyatnost. i Primenen., 12(2) (1967), 289-306. Theory Probab. Appl., 12(2) (1967), 251-266.

Weber, M. (1905). Die protestantische Ethik und der Geist des Kapitalismus (transl. The Protestant Ethic and the Spirit of Capitalism) 